\title{
Sistemática de Solução de Controvérsias do Mercosul: o Protocolo de Brasília e o Protocolo de Olivos
}

\author{
Eliane M. Octaviano Martins *
}

Resumo: O sistema originário de soluções de controvérsias no Mercosul era retratado pelo Protocolo de Brasília (PB) e pelo Protocolo de Ouro Preto (POP). Em 2002 o PB foi derrogado expressamente pelo Protocolo de Olivos (PO) para a Solução de Controvérsias no Mercosul. O novo sistema de solução de controvérsias do PO apresenta avanços significativos em relação à sistemática anterior.

Palavras-chave: Controvérsias, Mercosul, Protocolo de Brasília, Protocolo de Olivos.

Abstract: The originary system of solutions of controversies in the Mercosul was portraied for the Protocol of Brasilia (PB) and for the Protocol of Ouro Preto (POP). In 2002 the PB was repealed express by the Protocol of Olivos (PO) for the Solution of Controversies in the Mercosul the new system of solution of controversies of the $\mathrm{PO}$ presents significant advances in relation to previous systematics.

Keywords: Controversies, Mercosul, Protocol of Brasilia, Protocol of Olivos.

* Doutora pelo Programa de Pós-Graduação em Integração da América Latina da Universidade de São Paulo - PROLAM/USP; Professora de Direito Empresarial, Marítimo e Internacional em cursos de graduação e pós-graduação; Vice-Presidente do Instituto Paulista de Direito Comercial e da Integração - IPDCI. E-mail: emom@uol.com.br. Recebido em 08/03/06 e aceito em 12/06/06. 


\section{Introdução}

O presente estudo objetiva analisar o sistema de solução de controvérsias no Mercosul e respectivas inovaçóes advindas do Protocolo de Olivos (PO) cujos precedentes da sistemática do $\mathrm{PO}$ se consubstanciam na DEC. CMC No 25/00.

Inicialmente, analisar-se-á o sistema originário de soluções de controvérsias no Mercosul retratado pelo Protocolo de Brasília (PB) e pelo Protocolo de Ouro Preto (POP) indicando sua eficácia e sistemática procedimental.

Em subseqüência, será traçada abordagem do Protocolo de Olivos (PO), que institui um novo sistema de solução de controvérsias no Mercosul.

Finalizando a análise temática, pretende-se referenciar a eficácia da sistemática operacional atual consubstanciada no $\mathrm{PO}$ e sua contextualização prática.

\section{O sistema de solução de controvérsias no Mercosul}

O sistema originário de solução de controvérsias do Mercosul se baseava, inicialmente, no Protocolo de Brasília (PB), de $1991^{1}$, e no Anexo ao Protocolo de Ouro Preto (POP), de 1994.

Todavia, desde o julgamento dos três primeiros laudos arbitrais no Mercosul. foram detectadas algumas deficiências presentes no Protocolo de Brasília (PB) e se desponta a necessidade de instituição de uma nova sistemática visando a necessidade de garantir a correta interpretação, aplicação e cumprimento dos instrumentos fundamentais do processo de integração e do conjunto normativo do Mercosul. ${ }^{2}$

$\mathrm{Na}$ DEC. CMC No 25/00, adotada durante a XVIII Reunião do Conselho do Mercado Comum (Buenos Aires, 29/V/00), delegou-se ao Grupo Ad Hoc de Aspectos Institucionais (GAHAI), a feitura de uma proposta integral acerca do aperfeiçoamento do Sistema de Solução de Controvérsias do Protocolo de Brasília. Assim, a temática foi incluída na Agenda de Relançamento do Mercosul que encomendou ao GMC a elaboração de propostas de alteração do sistema de solução de controvérsias.

Consubstanciada na análise do GAHAI acerca do aperfeiçoamento do sistema de solução de controvérsias, foi adotada a DEC. CMC No 65/00.

\footnotetext{
${ }^{1}$ Regulamentado pela DEC. CMC N 17/98.

${ }^{2}$ Os Laudos Arbitrais estão disponíveis em: http://www.mercosur.org.uy .
} 
A partir de então, foram realizados uma série de encontros internacionais para proceder ao debate acerca do projeto de reformas ao atual sistema de solução de controvérsias no Mercosul.

Neste cenário, o texto do Protocolo de Olivos para a Solução de Controvérsias no Mercosul foi assinado em 18 de fevereiro de 2002, derrogando expressamente o PB. O PO e está em vigor internacionalmente desde janeiro de $2004 .{ }^{3}$ No Brasil o PO foi ratificado pelo Decreto Legislativo 712/03 e promulgado pelo Decreto 4.982/04.

Destarte, o Protocolo de Olivos (PO) objetivou implementar nova sistemática, de forma consistente e sistemática, visando consolidar a segurança jurídica, uma maior juridicidade e a melhoria procedimental do sistema de solução de controvérsias no Mercosul.

\section{A sistemática originária do Protocolo de Brasília}

Sob a égide da sistemática do Protocolo de Brasília (PB), permitia-se julgar alegaçóes de incumprimento das normas do Mercosul ${ }^{4}$ feitas por um Governo contra outro Governo, ou por um agente privado, que acionava seu Governo e este encaminhava o caso ao Governo do país objeto da reclamação - se considerasse a demanda justificada. ${ }^{5}$

O PB previa três fases: i) Negociações diretas entre as partes na controvérsia (15 dias); ii) Intervenção do GMC (30 dias); e iii) Tribunal Arbitral Ad Hoc (60 a 90 dias).

Nos termos do art. 21 do $\mathrm{PB}$, os laudos arbitrais eram "inapeláveis, obrigatórios para os Estados-Partes na controvérsia a partir da respectiva notificação e tinham, relativamente a eles, força de coisa julgada.” Deviam ser cumpridos em 15 dias, exceto se outro prazo fosse fixado pelo Tribunal. ${ }^{6}$

\footnotetext{
${ }^{3}$ Cf. Decisão MERCOSUL/CMC/DEC No. 37/03 (Regulamento do Protocolo de Olivos para solução de controvérsias no Mercosul, em vigor desde janeiro de 2004).

${ }^{4}$ Refere-se às controvérsias que surjam entre os Estado Partes sobre a interpretação, aplicação ou não cumprimento das disposições contidas no Trado de Assunção, assim como: Decisões CMC, Resoluções GMC, Diretrizes CCM.

${ }^{5} \mathrm{O}$ Capítulo V do PB era reservado para Reclamações de Particulares a respeito de medidas legais ou administrativas dos Estados Partes que violassem a normativa Mercosul. Tal Reclamação dependia de endosso da Seção Nacional para seguir adiante.

${ }^{6}$ Cf. ademais o sistema de consultas da Comissão de Comércio do Mercosul (Diretriz CCM N 17/99), que embora não constitua uma fase do sistema de solução de controvérsias, constitui um importante instrumento de troca de informações e formação de opinião. As consultas são apresentadas em cada reunião da CCM (de
} 
O mecanismo de solução de controvérsias do Mercosul foi acionado diversas vezes. Nove laudos arbitrais foram elaborados sob a vigência do $\mathrm{PB}^{7}$ :

No âmbito da sistemática de solução de controvérsias no Mercosul prevista no PB, possibilitava-se aos Estados-Partes do Mercosul submeterem seus litígios ao sistema arbitral do Mercosul e/ou solicitarem a instalação de um painel na OMC. Caracterizava-se a duplicidade de foro, visto que as disputas surgidas entre Estados-Partes de organizações de integração podem ser solucionadas tanto no âmbito regional quanto no multilateral. ${ }^{8}$

Existia, portanto, a possibilidade de que um litígio fosse julgado por diferentes sistemas de controvérsias, sendo que a opção, geralmente, é feita pela parte demandante. Destarte, ocorria o chamado forum shopping, ou seja, a possibilidade de escolha, por parte do demandante, de submeter o litígio à jurisdição que lhe fosse mais conveniente. ${ }^{9}$

Tal hipótese ocorreu na casuística envolvendo a Argentina sobre a reclamação feita pela República Federativa do Brasil à República Argentina sobre a aplicação de medidas antidumping contra a exportação de frangos inteiros, provenientes do Brasil (Res. 574/2000) do Ministério de Economia da República Argentina.

O caso foi analisado pelo Quarto Tribunal Arbitral, que decidiu serem os procedimentos de investigação e aplicaçáo antidumping da Argentina razoavelmente aceitáveis e não desviavam de sua finalidade. Assim, o Tribunal decidiu que o procedimento argentino referido e a Resolução ME 574/2000 do Ministério da Economia da Argentina com a qual culmina, não constituíam um descumprimento da regra de livre circulação de bens no Mercosul.

O Tribunal decidiu não anuir ao petitório da Parte Reclamante (Brasil) quanto à solicitação para que fosse declarado o descumprimento, pela Parte Reclamada (Argentina), das normas do MN e que por tal razão lhe ordenasse

regularidade mensal) e podem ser oriundas dos Estados ou de particulares que fazem chegar suas preocupações à Seção Nacional da CCM.

${ }^{7}$ Até março de 2005, nove tribunais ad hoc foram instituídos e todas as decisões proferidas foram devidamente cumpridas. Os Laudos Arbitrais estão disponíveis em: http://www.mercosur.org.uy .

${ }^{8}$ Cf. LOUREIRO, 2003, p. 261-273.

${ }^{9}$ A prática de "fórum shopping" ocorreu com bastante frequêencia sob a vigência do GATT 1947. Cf. OCTAVIANO MARTINS, 2005, p. 151. 
a revogação da resolução impugnada.

O Brasil, inconformado com a decisão, levou o caso à OMC que decidiu, em 2003, que a Argentina deveria modificar sua legislação de acordo com o disposto no Painel e as normas da OMC, o que será objeto de posterior análise.

A casuística ora analisada consagrou a duplicidade de foro, visto que o mesmo litígio foi submetido ao sistema arbitral (IV Laudo Arbitral) do Mercosul e também ao órgão de solução de controvérsias (OSC) da OMC, sendo proferidas, portanto, duas decisóes sobre a temática. ${ }^{10}$

\section{A sistemática de solução de controvérsias do Protocolo de Olivos}

O Protocolo de Olivos (PO), artigo $4^{\circ}$ estabelece que os Estados-Partes, numa controvérsia, procurarão resolvê-la, antes de tudo, mediante negociaçóes diretas. Estas não poderão, salvo acordo entre as partes, exceder o prazo de quinze (15) dias a partir da data em que uma delas comunicou à outra a decisão de iniciar a controvérsia. ${ }^{11}$ Os Estados-Partes em uma controvérsia informarão ao Grupo Mercado Comum, por intermédio da Secretaria Administrativa do Mercosul, sobre as gestóes que se realizarem durante as negociaçóes e os resultados das mesmas. Se, mediante as negociaçóes diretas, não se alcançar um acordo, ou se a controvérsia for solucionada apenas parcialmente, qualquer dos Estados-Partes na controvérsia poderá iniciar diretamente o procedimento arbitral. ${ }^{12}$

O novo sistema de solução de controvérsias do $\mathrm{PO}$ apresenta avanços significativos em relação à sistemática anterior do $\mathrm{PB}$, dentre os quais se destacam:

\footnotetext{
${ }^{10}$ A possibilidade de dupla jurisdição, e acesso simultâneo ao Tribunal Arbitral do MERCOSUL e ao OSC da OMC existia, sob a égide do Protocolo de Brasília. Para Loureiro (2003, p. 8), a utilização dos dois foros, "além de enfraquecer o processo de integração do MERCOSUL, tendo em vista a total indiferença apresentada em relação à decisão proferida no âmbito regional, também é causador de um ambiente instável, sem a segurança jurídica necessária às relações internacionais. Além de que, a submissão aos dois foros é responsável por um prolongamento desnecessário dos litígios, perpetuando o clima de instabilidade entre os envolvidos."

${ }^{11}$ A respeito do tema consulte: BARRAL, 2001b, p. 53-65; BAPTISTA, 1997, p. 178-186; REYES, 2000, p. 159-169; COSTA, 1997, p. 177-187.

${ }^{12}$ Cf. PO, art. 4 e ss. e art. 14 da DEC CMC No 37/03.
} 
a) Criação de um Tribunal Permanente de Revisão (TPR);

b) Implementação de mecanismos de regulamentação das Medidas compensatórias;

c) Criação de normas procedimentais inspiradas no modelo da OMC, como as que determinam que o objeto da controvérsia seja limitado na reclamaçáo e resposta apresentadas ao Tribunal $A d$ hoc;

d) Intervenção opcional do GMC;

e) Possibilidade de eleição de foro; e

f) Possibilidade de Reclamação dos Particulares.

\section{Tribunal Permanente de Revisão (TPR)}

Inspirado no modelo da OMC, o TPR foi instalado dia 13 de agosto de 2004, em Assunção, Paraguai.

Ele será responsável por maior homogeneidade nas decisóes proferidas no sistema do Mercosul, delegando maior estabilidade e confiabilidade.

$\mathrm{O} \mathrm{PO}$, inobstante derrogue expressamente o $\mathrm{PB}$, não adota um sistema permanente à solução de controvérsias para o Mercosul, conforme a previsão originária do TA. ${ }^{13}$ Mantém a transitoriedade, condicionando essa nova revisão à futura convergência de uma Tarifa Externa Comum para o Mercosul. ${ }^{14}$ Ademais, o mecanismo de solução de controvérsias instituído pelo $\mathrm{PO}$ não derroga o mecanismo de solução de diferendos existente no âmbito da Comissão de Comércio do Mercosul, estabelecido pelo anexo do POP. ${ }^{15}$

\footnotetext{
${ }^{13}$ PO, art. 55: "Artigo 55. Derrogação. 1. O presente Protocolo derroga, a partir de sua entrada em vigência, o Protocolo de Brasília para a Solução de Controvérsias, adotado em 17 de dezembro de 1991 e o Regulamento do Protocolo de Brasília, aprovado pela Decisão CMC 17/98. 2. Não obstante, enquanto as controvérsias iniciadas sob o regime do Protocolo de Brasília não estejam concluídas totalmente e até se completarem os procedimentos previstos no artigo 49, continuará sendo aplicado, no que corresponda, o Protocolo de Brasília e seu Regulamento.3. As referências ao Protocolo de Brasília que figuram no Protocolo de Ouro Preto e seu Anexo, entendem-se remetidas, no que corresponda, ao presente Protocolo."

${ }^{14}$ PO, Artigo 53: "Revisão do Sistema. Antes de culminar o processo de convergência da tarifa externa comum, os Estados Partes efetuarão uma revisão do atual sistema de solução de controvérsias, com vistas à adoção do Sistema Permanente de Solução de Controvérsias para o Mercado Comum a que se refere o numeral 3 do Anexo III do Tratado de Assunção." ${ }^{15}$ Cf. COUTINHO (2004, p. 5) "Indubitavelmente, o Tribunal Permanente de Revisão é considerado a maior inovação trazida pelo Protocolo, pois representa um aperfeiçoamento do sistema jurisdicional, conferindo dinamismo ao sistema de resolução de diferendos. Seu advento implica fundamentalmente na obtenção de maior coerência entre as decisões exaradas pelos tribunais arbitrais ad hoc, edificando uma jurisprudência
} 
Efetivamente, destacam-se três funções significativas para o $\mathrm{TPR}^{16}$ : a função de instância recursal, a de órgão de instância única e a consultiva.

A sistemática implementada pelo POP não abandona a figura dos tribunais arbitrais ad hoc ${ }^{17}$; apenas lhes agrega o órgáo jurisdicional. ${ }^{18}$

Os arbitrais ad hoc serão suprimidos apenas nos casos em que as partes, voluntariamente, decidam se submeter, em única instância, ao TPR. ${ }^{19}$ Exclusivamente nestes casos, o TPR assume a função de órgão de instância única. ${ }^{20}$ Nessas condiçóes, os laudos do TPR serão obrigatórios para os Estados-Partes na controvérsia, a partir do recebimento da respectiva notificação, não estaráo sujeitos a recursos de revisáo e terão, com relaçáo às partes, força de coisa julgada (PO, art. 23, 2).

\section{A função recursal do TPR}

No que tange à função recursal, o PO estabelece um procedimento de revisão no art. 17, dispondo que qualquer das partes na controvérsia poderá apresentar um recurso de revisão do Laudo do Tribunal Arbitral Ad Hoc ao TPR, em prazo não-superior a quinze (15) dias a partir da sua notificação. Todavia, o recurso estará limitado a questóes de direito tratadas na controvérsia e às interpretaçóes jurídicas desenvolvidas no Laudo do Tribunal Arbitral Ad Hoc. Vale destacar que os laudos dos Tribunais $A d H o c$ emitidos com base

uniformizadora que visa evitar a adoção de interpretações divergentes nas causas que forem submetidas aos tribunais do Mercosul. Com a criação deste Tribunal Permanente, abriu-se a possibilidade de haver um órgão de integração homogênea e compromissado com a articulação entre os laudos. Desta forma, ainda que existam tribunais ad hoc, será possível a criação de um Direito genuíno no bloco, permitindo criar-se uma orientação jurisprudencial que irá proporcionar maior segurança jurídica não apenas aos particulares, mas também aos Estados membros, emitindo-lhes uma mensagem de alerta na medida em que serve como um dique de contenção para sua tendência natural à unilateralidade no momento em que surge a controvérsia."

${ }^{16} \mathrm{~A}$ respeito da composição, disponibilidade e funcionamento do Tribunal Permanente de Revisão v. PO, artigo 18 a 20 e arts. 32 e ss. da DEC da CMC No. 37/03.

17 Cf. DEC CMC No. 37/03 e Artigo 46 referente ao início do trâmite (art. 40 PO).

${ }^{18} \mathrm{Cf}$. PO, arts. 10 a 16.

${ }^{19}$ Cf. artigo 40 da DEC CMC No. 37/03 (Regulamento do Protocolo de Olivos para solução de controvérsias no Mercosul) a respeito do conteúdo, notificação e publicação dos laudos arbitrais (art. 16, 22 e 25 PO).

${ }^{20}$ Cf. PO, artigo 23: "Acesso direto ao Tribunal Permanente de Revisão: 1 . As partes na controvérsia, culminado o procedimento estabelecido nos artigos 4 e 5 deste Protocolo, poderão acordar expressamente submeter-se diretamente e em única instância ao Tribunal Permanente de Revisão, caso em que este terá as mesmas competências que um Tribunal Arbitral Ad Hoc, aplicando-se, no que corresponda, os Artigos 9, 12, 13, 14, 15 e 16 do presente Protocolo." Cf. Artigo 39 da DEC da CMC No. 37/03. 
nos princípios ex aequo et bono não serão suscetíveis de recurso de revisão. ${ }^{21}$

Especificamente à função consultiva, o PO estabelece a possibilidade de o TPR funcionar como uma jurisdição consultiva. ${ }^{22}$

\section{Revisão do Laudo Arbitral do Tribunal Arbitral Ad Hoc, de 25 de outubro de 2005, na controvérsia "Proibição de Importação de Pneumáticos Remodelados Procedentes do Uruguai"}

O Tribunal Permanente de Revisão (TPR) do MERCOSUL emitiu, em dezembro de 2005, seu primeiro laudo acerca de um recurso apresentado pelo Uruguai contra o Laudo Arbitral do Tribunal Arbitral Ad Hoc, de 25 de outubro de 2005, na controvérsia "Proibição de Importação de Pneumáticos Remodelados Procedentes do Uruguai”.

O Laudo $\mathrm{N}^{\circ}$ 01/05 foi emitido no dia 20 de dezembro, em Assunção, Paraguai, sede do TPR do MERCOSUL.

O laudo inclui numerosas considerações técnico-jurídicas extremamente importantes para o futuro do bloco, essencialmente no que tange a interpretação das exceçôes ao livre comércio intra-regional. O TPR destacou em seu ditame que não há dois princípios em conflito ou confronto como equivocadamente se afirmara no laudorevisado. Efetivamente, existe apenas um princípio do livre comércio, ao qual se podem antepor certas exceçóes, v.g., a proteção ambiental. O TRP também não concordou com o que foi afirmado pelo laudo em revisão, que estipulava que o Tribunal vai ponderar a aplicação dos mencionados princípios de confronto (livre comércio e proteção de meio ambiente), definindo a prevalência de um sobre o outro, e levando em conta o direito internacional.

O TPR entendeu que a questão debatida é a viabilidade ou não da exceção relativa ao meio ambiente, segundo a normativa do MERCOSUL, e não ao teor do direito internacional e considerou que, embora os princípios e disposiçóes do direito internacional estejam incluídos no PO como um dos referentes jurídicos a serem aplicados (Art. 34), sua aplicação deve ser sempre

\footnotetext{
${ }^{21}$ Nos termos do art. 22, o Tribunal Permanente de Revisão poderá confirmar, modificar ou revogar a fundamentação jurídica e as decisões do Tribunal Arbitral Ad Hoc. O laudo do Tribunal Permanente de Revisão será definitivo e prevalecerá sobre o laudo do Tribunal Arbitral Ad Hoc. Cf. Artigo 36 e 37 da DEC da CMC No. 37/03.

${ }^{22}$ Cf. arts. 2a․ a 8aㅡ da DEC CMC N 37/03. A possibilidade de elaboração de opiniões consultivas pelo TPR possibilita interpretação uniforme ao direito de integração. Cf. LOUREIRO, 2003, p. 6.
} 
e unicamente de forma subsidiária (ou, no pior dos casos, complementar). Destarte, a aplicação não ocorre de maneira direta e primária, como evidentemente ocorre no direito comunitário. Todavia, a sistemática do Mercosul ainda é institucional. Em seguida, o TRP argumentou que o direito de integração tem e deve ter suficiente autonomia em relaçáo aos outros ramos do Direito, visto que, se não o tiver, estará contribuindo sempre de maneira negativa ao desenvolvimento da institucionalidade do bloco subregional, argumentou o organismo de revisão. No que tange à invocação da exceção concreta ao livre comércio, o TPR afirmou que quem a invoca, deve prová-la.

Entretanto, esclareceu que não existe no MERCOSUL um corpo legal que estabeleça clara e concretamente os critérios de rigor a serem analisados para a invocação de tais exceçóes, as quais sempre devem ser interpretadas com critério restritivo.

Concluiu finalmente o TPR que a decisão arbitral em revisão possui evidentes e graves erros jurídicos que "tornam imperiosamente revogável" o laudo em questão. Em conseqüência, e conforme as normas e princípios jurídicos aplicáveis ao acaso, decidiu-se, por maioria, revogar o laudo arbitral de 25 de outubro de 2005 . Ademais, determinou, também, que a lei argentina envolvida na questão $\left(\mathrm{N}^{\circ} 25.626\right)$ é incompatível com a normativa MERCOSUL e, portanto, esse país deverá derrogá-la ou modificá-la dentro do prazo de cento e vinte dias corridos. ${ }^{23}$

A decisão do TPR estará em vigor até que o MERCOSUL aprove uma normativa a ser negociada, sobre importação de pneumáticos remodelados.

\section{Mecanismos de regulamentação das medidas compensatórias}

$\mathrm{O}$ PO procedeu à implementação de mecanismos de regulamentação das medidas compensatórias na hipótese de não-cumprimento do Laudo do Tribunal Arbitral, diferentemente do PB, que atribuía exclusivamente a

\footnotetext{
${ }^{23}$ A Argentina, a partir da notificação do laudo do TPR, está impedida de adotar ou empregar qualquer medida que seja contrária a este pronunciamento ou que crie obstáculos a sua aplicação.
} 
aplicabilidade de tais medidas a um ato unilateral dos Estados. ${ }^{24}$ Também incluiu normativas para racionalizar o quantum, a extensão das medidas e sua duração. ${ }^{25}$

\section{Intervenção opcional do GMC}

Sob a égide do PO, a intervenção do GMC é procedimento facultativo, opcional $^{26}$, dependendo de acordo entre as partes, visando agilizar os procedimentos de solução dos litígios. ${ }^{27}$

Faculta-se, ademais, a um terceiro Estado que não seja parte na controvérsia, solicitar a intervenção ao GMC. ${ }^{28}$

\section{Eleição de foro}

As controvérsias entre os Estados-Partes sobre a interpretação, a aplicação ou o não-cumprimento do TA, do POP, dos protocolos e acordos celebrados no marco do TA, das Decisóes do CMC, das Resoluçóes do GMC e das Diretrizes da CCM serão submetidas aos procedimentos estabelecidos no PO e seu respectivo Regulamento (DEC. CMC N³7/03) ${ }^{29}$.

\footnotetext{
${ }^{24}$ Nos termos do art. 31 do POP, in verbis. "Art. 31. Medidas Compensatórias. Artigo 31. Faculdade de Aplicar Medidas Compensatórias. 1. Se um Estado parte na controvérsia não cumprir total ou parcialmente o laudo do Tribunal Arbitral, a outra parte na controvérsia terá a faculdade, dentro do prazo de um (1) ano, contado a partir do dia seguinte ao término do prazo referido no artigo 29.1, e independentemente de recorrer aos procedimentos do artigo 30, de iniciar a aplicação de medidas compensatórias temporárias, tais como a suspensão de concessões ou outras obrigações equivalentes, com vistas a obter o cumprimento do laudo. 2. O Estado Parte beneficiado pelo laudo procurará, em primeiro lugar, suspender as concessões ou obrigações equivalentes no mesmo setor ou setores afetados. Caso considere impraticável ou ineficaz a suspensão no mesmo setor, poderá suspender concessões ou obrigações em outro setor, devendo indicar as razões que fundamentam essa decisão. 3. As medidas compensatórias a serem tomadas deverão ser informadas formalmente pelo Estado Parte que as aplicará, com uma antecedência mínima de quinze (15) dias, ao Estado Parte que deve cumprir o laudo." A respeito da faculdade de questionar medidas compensatórias, v. art. 32 do PO." A respeito da proporcionalidade das medidas compensatórias, Cf. art. 32. 2 PO e art. 44 da DEC CMC N. 37/03.

${ }^{25}$ Foram instituídos critérios para os limites da retaliação que será efetuada pelo Estado beneficiado pela decisão arbitral. Cf. COUTINHO, 2004, p. 5.

${ }^{26}$ Cf. art. 6 do PO e art. 15 da Intervenção do Grupo Mercado Comum da DEC. CMC N. 37/03.

${ }^{27}$ Para o PB tal etapa figurava como obrigatória.

${ }^{28}$ Cf. art. 6.3 do PO e artigo 16 da DEC. CMC N. 37/03 a respeito da Intervenção do GMC a pedido de um Estado que não seja parte na controvérsia.

29 Não necessita ser incorporada aos ordenamentos jurídicos nacionais dos Estados Partes por regulamentar aspectos do funcionamento ou da organização do Mercosul.
} 
Nos casos de controvérsias compreendidas no âmbito de aplicação do PO e que possam também ser submetidas ao sistema de soluçáo de controvérsias da OMC ou de outros esquemas preferenciais de comércio de que sejam parte individualmente, os Estados-Partes do Mercosul poderáo se submeter a um ou outro foro, à escolha da parte demandante. Sem prejuízo disso, as partes poderão, de comum acordo, definir o foro.

Uma vez iniciado um procedimento de solução de controvérsias no foro escolhido, nenhuma das partes poderá recorrer a mecanismos de solução de controvérsias estabelecidos nos outros foros com relação a um mesmo objeto $^{30}$, ou seja, a eleição é excludente.

Evidencia-se que a eleição de foro será uma prerrogativa da parte demandante, exceto estipulação em contrário das partes envolvidas na controvérsia. ${ }^{31}$ Neste contexto, admite-se que as controvérsias surgidas no âmbito do PO sejam resolvidas por outros sistemas de solução de controvérsias, desde que possuam competência para tanto, como o sistema da OMC ou outros esquemas preferenciais de que os Estados-Partes do Mercosul participem de maneira individual. Mister se faz relevar que, em sendo a eleição de foro excludente, evitar-se-á a duplicidade de procedimentos e também que soluçóes contraditórias sejam proferidas para um mesmo litígio.

\section{Possibilidade de reclamação dos particulares}

Outra importante inovação trazida pelo PO se consubstancia na previsão das reclamaçóes de particulares, há muito demandadas pelos agentes privados, também legítimos atores no processo integracionista. ${ }^{32}$

Os trâmites relativos às reclamaçôes de particulares estão normatizados nos art. 39 a 41 do PO.

O procedimento de reclamaçóes efetuadas por particulares (pessoas físicas ou jurídicas) será aplicável em razão da sanção ou aplicação, por qualquer

${ }^{30}$ Cf. art. 14 do PO.

${ }^{31}$ DREYSIN de KLOR (2002, passim.) destaca algumas desvantagens do sistema de eleição de foro. Evidencia que, além do enfraquecimento do sistema de integração regional há a possibilidade de ocorrência de fórum shopping, o que considera aceitável em um uma área de livre comércio, como nos exemplos acima destacados, mas apresentaria inconvenientes em um processo de maior profundidade, como o que se pretende para 0 bloco sul americano.

${ }^{32}$ Cf. FURLAN, 2004, p. 2. 
dos Estados-Partes, de medidas legais ou administrativas de efeito restritivo, discriminatórias ou de concorrência desleal, em violação do TA, do POP, dos protocolos e acordos celebrados no marco do TA, das Decisóes do CMC, das Resoluçóes do GMC e das Diretrizes da CCM (art. 39 do PO).

Iniciar-se-á o trâmite com a formalização das reclamações ante a Seção Nacional do GMC do Estado-Parte em que tenham sua residência habitual ou a sede de seus negócios. ${ }^{33}$

$\mathrm{O}$ arts. 40 e 46 da DEC. CMC N $\mathrm{N}^{\circ}$ 37/03 impóem a obrigatoriedade de as reclamaçóes serem apresentadas por escrito perante à respectiva Seção Nacional do GMC, em termos claros e precisos, incluindo, em especial:

a) A identificação do particular reclamante, seja pessoa física ou jurídica, e seu domicílio;

b) A indicação das medidas legais ou administrativas que configurariam a violação alegada aos tratados e às normas do Mercosul;

c) A determinação da existência ou da ameaça de prejuízo;

d) Relação causal entre a medida questionada e a existência ou ameaça de prejuízo;

e) Os fundamentos jurídicos em que se baseiam; e

f) A indicação dos elementos de prova apresentados.

Os particulares afetados deverão fornecer elementos que permitam determinar a veracidade da violação e a existência ou ameaça de um prejuízo, para que a reclamação seja admitida pela Seção Nacional e avaliada pelo GMC e pelo grupo de especialistas, se convocado.

Admitida a reclamação dos particulares pela Seção Nacional do GMC, e frustradas as negociaçóes diretas entre as partes, o GMC convocará o grupo de especialistas do Mercosul para a emissão de parecer. ${ }^{34}$

\section{Solução de conflitos entre o Mercosul e terceiros países}

AscontrovérsiassurgidasentreosEstados-PartesdoMercosuleterceirospaíses serão solucionadas no âmbito da OMC.

Nos casos envolvendo Bolívia e Chile, os conflitos podem ser resolvidos

\footnotetext{
${ }^{33}$ No Brasil, é coordenada pelo Subsecretário-Geral da América do Sul, do Ministério das Relações Exteriores.

${ }^{34}$ Cf. POP, arts. 41 a 43.
} 
ao amparo dos regimes de solução de controvérsias previstos nos acordos de livre comércio celebrados com o Mercosul. ${ }^{35}$

\section{Considerações finais}

Inobstante significativas alteraçóes, o sistema de solução de controvérsias adotado pelo PO continua seguindo o modelo arbitral, apesar das discussóes e opinióes que asseveram a necessidade da adoção de um sistema judicial de solução de conflitos consubstanciado em uma ordem jurídica supranacional, assim como ocorreu na União Européia, que assegura uniformidade de interpretação e aplicação.

O sistema de resolução de controvérsias do Mercosul ainda se mantem edificado sobre os princípios do pragmatismo, realismo e gradualismo e, consequentemente, tem proporcionado uma maior flexibilidade.

Com efeito, a flexibilidade do sistema de solução de constrovérsias do Mercosul favorece a solução negociada, fundamental para países que têm de lidar com uma constante instabilidade política e econômica, bem como com os abalos sofridos por influência políticas externas ${ }^{36}$, todavia ainda não possibilita a segurança jurídica necessária e desejável para avanços significativos no processo de integração.

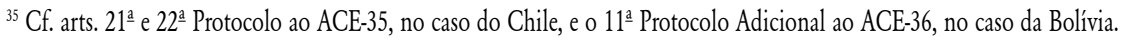
Os textos estão disponíveis em http://www.aladi.org .

${ }^{36}$ Afirma Coutinho (2004, p. 16) que, "sem desconsiderar-se o papel que tem o Tribunal de Justiça das Comunidades Européias para a integração comunitária, é fundamental observar-se que os processos de integração mercosulino e europeu são distintos em diversos aspectos e se encontram em diferentes patamares de evolução, pois que o Mercosul encontra-se ainda em uma fase embrionária, e busca firmar-se como uma União Aduaneira, esperando a consolidação da Tarifa Externa Comum, prevista para 2006.”
} 


\section{Referencias Bibliográficas}

AMARAL JÚNIOR, Alberto do. (Coord.). OMC e o comércio internacional. São Paulo: Aduaneiras, 2002, p. 261-273.

BARRAL, Welber Oliveira. O novo sistema de solução de controvérsias do Mercosul. Revista da Ordem dos Advogados do Brasil, Rio de Janeiro, v. 31, n. 73, p. 53-65, jul.-dez. 2001 b.

BAPTISTA, Luiz Olavo. Solução de divergências no Mercosul. In: BASSO, Maristela. (Org.). Mercosul: seus efeitos jurídicos, econômicos e políticos nos Estados membros. 2. ed. Porto Alegre: Livraria do Advogado, 1997.

COSTA, Lígia Maura. Tribunais supranacionais e aplicação do direito comunitário: aspectos positivos e negativos. In: VENTURA, Deisy de Freitas Lima. (Org.). Direito Comunitário do Mercosul. Porto Alegre: Livraria do Advogado, 1997.

COUTINHO, Kalyani Rubens Muniz. Protocolo de Olivos: um novo sistema de solução de controvérsias para o Mercosul. Brasília, n. 0010, setembro. 2004. 16 p. Disponível em: <http://www.avocato.com.br/doutrina/ed0010.2004. gui0003.htm>. Acesso em: 2 de fevereiro de 2005.

FURLAN, Fernando de Magalhães. O tribunal do Mercosul. Foro Empresarial, Evento IV Plenária do MEBF em Brasília, 02 de setembro de 2004.

LOUREIRO, Patrícia. Duplicidade de foro no direito internacional: a OMC e o Mercosul. Florianópolis: Instituto de Relaçóes Internacionais, 2003, p. 3. Disponível em: <http:www.iribr.com/cancun/patrícia_ loureiro.asp>. Acesso em: novembro de 2004 .

OCTAVIANO MARTINS, Eliane Maria. Defesa da concorrência x defesa comercial no Mercosul. São Paulo, 2005. Tese (Doutorado em Integração da América Latina) - Programa de Pós-Graduação em Integração da América Latina da Universidade de Sáo Paulo, 2005.

OCTAVIANO MARTINS, Eliane Maria. A sistemática de solução de controvérsias no âmbito da OMC. Revista de Direito Internacional Econômico, v. 2, n. 5, p. 61-70, 2003. 
REYES, Jorge Enrique Fernández. Evaluación de los mecanismos de solución de controvérsias en el Mercosur. Revista de Direito Internacional e Mercosul, Buenos Aires, n. 4, p. 159-169, ago. 2000. 